\title{
Low Cost and High Performance Single Phase UPS Using a Single-Loop Robust Voltage Controller
}

\author{
Jun-Keun $\mathrm{Ji}^{\dagger}$, Dae-Kwan $\mathrm{Ku}^{*}$, and Seung-Beom Lim ${ }^{* *}$ \\ ${ }^{\dagger}$ Department of Electrical Engineering, Soonchunhyang University, Asan, Korea \\ *VCTech Co., Ltd., R\&D Center, Gunpo, Korea \\ ${ }^{* *}$ EON Co., Ltd., R\&D Center, Anyang, Korea
}

\begin{abstract}
Uninterruptible Power Supplies (UPSs) can be largely divided into the passive-standby, line-interactive and double-conversion methods. This paper proposes a double-conversion UPS with a low cost and high performance. This single phase UPS uses a single-loop robust voltage controller and 1-switch voltage doubler strategy PFC. The proposed UPS is composed of a single phase PFC, a half-bridge inverter, a battery charger and a battery discharger. Finally, the validity of proposed UPS was verified by various experimental tests.
\end{abstract}

Key words: 1-switch voltage doubler strategy PFC, Low cost and high performance, Single phase UPS, Single-loop robust voltage controller

\section{INTRODUCTION}

The main objective of uninterruptible power supply (UPS) systems is to supply a sinusoidal voltage with a constant amplitude and frequency to critical loads such as industry controllers, computers and communication systems without interruptions and irrespective of load and supply conditions [1], [2].

Generally, an ideal UPS should be able to deliver an uninterrupted power and simultaneously provide the necessary power conditioning for a particular power application. Therefore, it should have the following features: a regulated sinusoidal output voltage with a low total harmonic distortion (THD) independent of changes in the input voltage or load, on-line operation that means a zero switching time from the normal mode to the stored energy mode and vice versa, a low THD sinusoidal input current and a near unity power factor, high efficiency, low maintenance, low cost, low weight, and compact size [3].

UPSs are largely divided into three kinds of UPS

Manuscript received Jan. 7, 2015; accepted Feb. 21, 2015

Recommended for publication by Associate Editor Younghoon Cho.

${ }^{\dagger}$ Corresponding Author: jkji@sch.ac.kr

Tel: +82-41-530-1371, Soonchunhyang University

*VCTech Co., Ltd., R\&D Center, Gunpo, Korea

${ }^{* *}$ EON Co., Ltd., R\&D Center, Anyang, Korea topologies: passive-standby (off-line UPS), line-interactive and double-conversion (on-line UPS) methods [1]. The main advantages of double-conversion UPS systems are their very wide tolerance to input voltage variations and their highly precise regulation of output voltage. In addition, there is no transfer time during the transition from the normal mode to the stored energy mode. The main disadvantages of the conventional double-conversion UPS topology are its low power factor, high THD at the input, and low efficiency. The input rectifier deteriorates the quality of the input current unless an extra power factor correction (PFC) circuit, which increases the system cost, is added [4]-[13].

In addition, UPS systems are required for supplying a sinusoidal output voltage for linear and nonlinear loads. They must be highly reliable and have a quick dynamic response. Many control strategies have been applied to UPS inverters. Generally, the tasks of output voltage control for UPS inverters is to provide a fast dynamic responses and to maintain a perfect sinusoidal voltage waveform even with nonlinear or changing loads. To achieve these aims, many controllers have been proposed in the literature [14]-[20].

This paper proposes a double-conversion UPS with a low cost and high performance. It is a single phase UPS using 1-switch voltage doubler strategy PFC and a single-loop robust voltage controller. The validity of proposed UPS was verified by various experimental tests. 


\section{Proposed Single PhASE UPS}

Fig. 1 shows the proposed single phase double-conversion UPS system. The UPS is composed of single phase 1-switch voltage doubler strategy PFC, a half-bridge inverter, a battery charger and a battery discharger [21].

The proposed single-phase double-conversion UPS supplies energy to the load by the PFC and inverter operations, and it charges the battery with the charger. When the UPS is in normal operation, the PFC controls a constant DC bus voltage, and the inverter serves to supply a stable voltage by converting DC voltage into a sinusoidal AC voltage at the load. When the input source power is unstable or outgoing, the battery discharger and inverter operate with a battery to supply energy to the load using the energy stored in the battery. DC voltage is made constant by a push-pull battery discharger using the battery voltage. The inverter operates in a way that is similar to the normal operation. The bypass switch operates during inverter overload or faulty conditions, and supplies commercial power supply to the load.

The proposed UPS operates in three operating modes: normal mode, battery mode, and the bypass mode, as shown in Fig. 2.

The normal mode is the same as in Fig. 2(a). The input current and the DC link voltage are controlled through the PFC which receives the input from the AC power, and the inverter controls a $220 \mathrm{~V} / 60 \mathrm{~Hz}$ output voltage to be supplied to the load. At this time, the battery charger charges the battery. The battery mode is the same as in Fig. 2(b). This mode is operated during abnormal input voltage or overload conditions. In this mode the DC link voltage is raised back to a constant voltage through the push-pull converter using the battery voltage. In addition, the inverter controls a $220 \mathrm{~V} / 60 \mathrm{~Hz}$ output voltage and supplies the energy to the load. The bypass mode is the same as in Fig. 2(c). This mode is operated during long-duration inverter overload or fault conditions, and it supplies input power to the load via the bypass STS.

\section{CONTROL STRATEGY}

\section{A. PFC Control Strategy}

The proposed UPS uses a single-phase PFC converter with the 1-switch voltage doubler strategy for the single-phase double-conversion UPS. The PFC converter needs a diode bridge and one bidirectional active switch. Thus, it is possible to reduce the material cost [22].

Fig. 3 shows the entire structure of the PFC controller. The DC Link voltage controller uses a PI controller. In addition, the output of the PI balancing controller, which is operated with respect to the top and bottom capacitor voltage difference for compensating the DC capacitor voltage

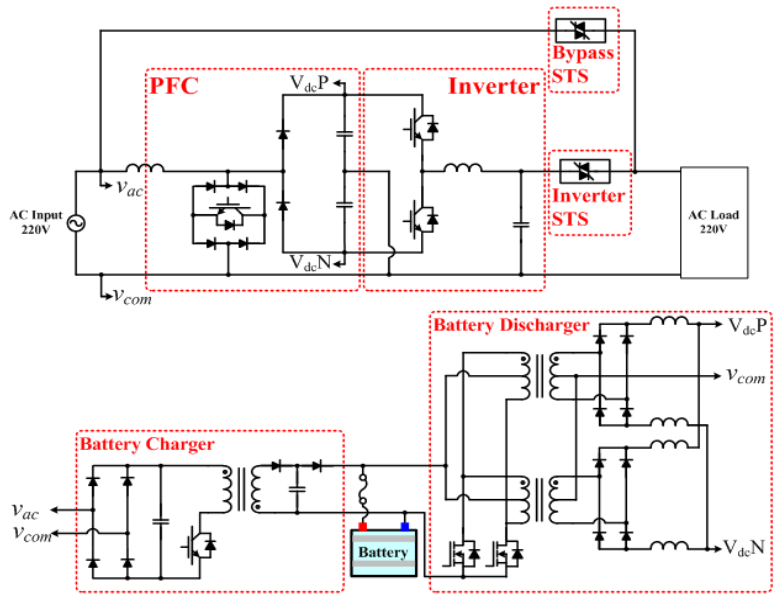

Fig. 1. Proposed UPS for low cost and high performance.

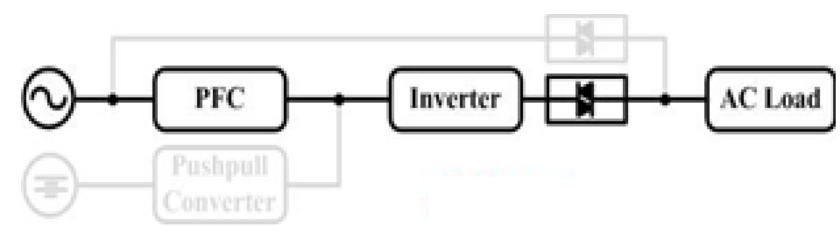

(a)

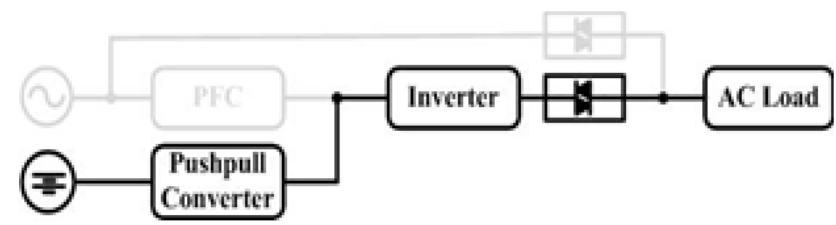

(b)

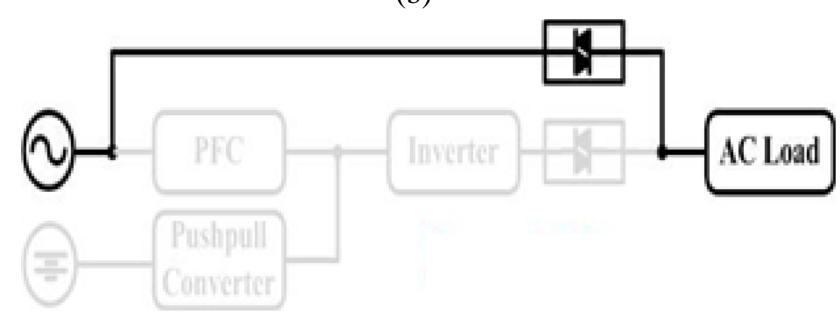

(c)

Fig. 2. Operation in each mode. (a) Normal mode. (b) Battery mode. (c) Bypass mode.

unbalance, is added to the input current controller (CC). The input current controller uses a PI controller, and is uses the absolute value in the input current control in order to reduce the zero-crossing distortion. In addition, duty feedforward compensation is also added to the output of the current controller in order to reduce the leading phase effect of the input current [23]. Additionally, the $120 \mathrm{~Hz}$ mean value of the DC bus voltage is used on the DC bus voltage control and the duty feedforward compensation.

Fig. 4 shows a block diagram of a PI current controller. The performance of the PI current controller is experimentally tested to confirm the input current reference tracking, input power factor correction and input current THD suppression [23]. 


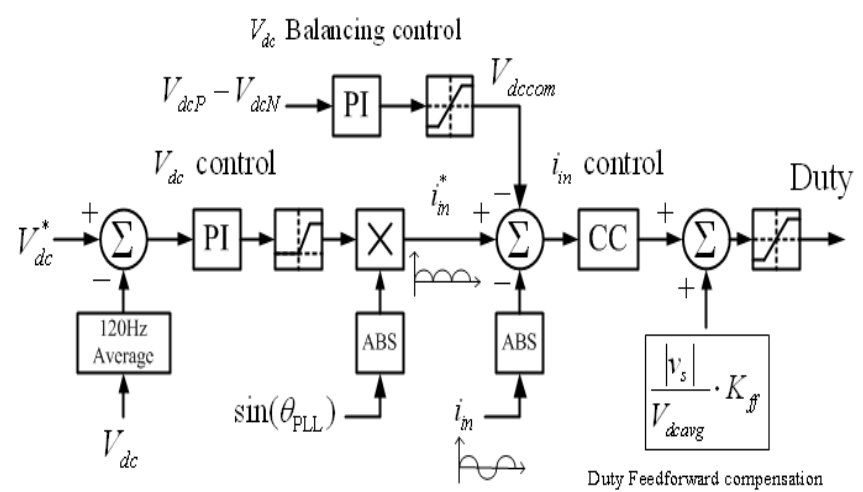

Fig. 3. Entire structure of PFC controller.

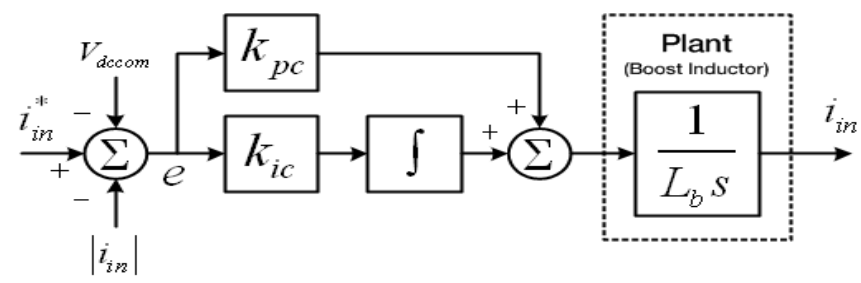

Fig. 4. Block diagram of the PI current controller.

The closed loop transfer function of the designed current controller and the gains of the PI current control are same as Eq. (1) and (2).

$$
\begin{gathered}
\frac{i_{i n}}{i_{i n}^{*}}=\frac{2 \zeta_{c} \omega_{n c} s+\omega_{n c}^{2}}{s^{2}+2 \zeta_{c} \omega_{n c} s+\omega_{n c}^{2}} \\
k_{p c}=2 \zeta_{c} \omega_{n c} L_{b}, k_{i c}=\omega_{n c}^{2} L_{b}\left(\omega_{n c}=2 \pi f_{n c}\right)
\end{gathered}
$$

\section{B. Inverter Voltage Control Strategy}

The voltage control of the proposed UPS inverter utilizes a single loop robust voltage controller. The voltage controller is designed using a $\mu$-based robust control scheme to simultaneously guarantee robust stability and robust tracking performance in the presence of load variations [24]. The authors of [24] proposed a new method using the rated outputs and power factor in order to express the uncertainty of the load.

Fig. 5 shows the permissible range of power that can be driven normally in the UPS system which has the rated output power $\mathrm{S}$, which is the active power $\mathrm{P}$ and the power factor PF.

Here, the reactive power Q is calculated as follows:

$$
\mathrm{Q}=\sqrt{\mathrm{S}^{2}-\mathrm{P}^{2}}=\sqrt{\left(\frac{P}{P F}\right)-P^{2}}
$$

In addition, the relationship between the power and the impedance is as follows:

$$
\mathrm{S}=\mathrm{P}+\mathrm{jQ}=\frac{\mathrm{V}_{\mathrm{o}}^{2}}{\mathrm{Z}}
$$

Where, $\mathrm{V}_{\mathrm{o}}$ is the rated voltage.

The impedance is the reciprocal of the admittance, which has a conductance $G$ and susceptance $B$. Therefore, the admittance may be expressed as follows:

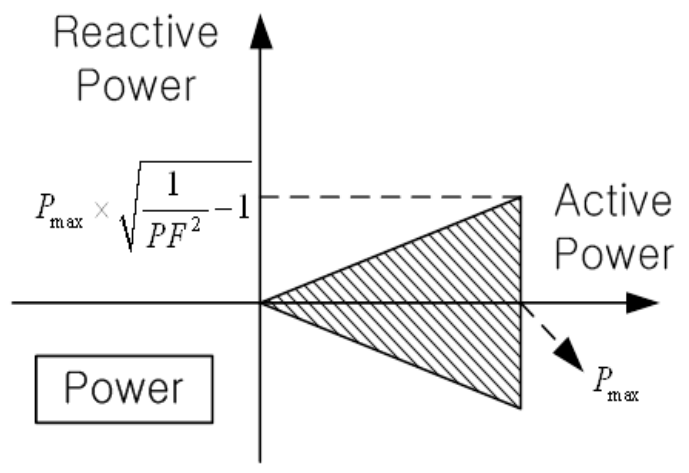

Fig. 5. Permissible range of active and reactive power.

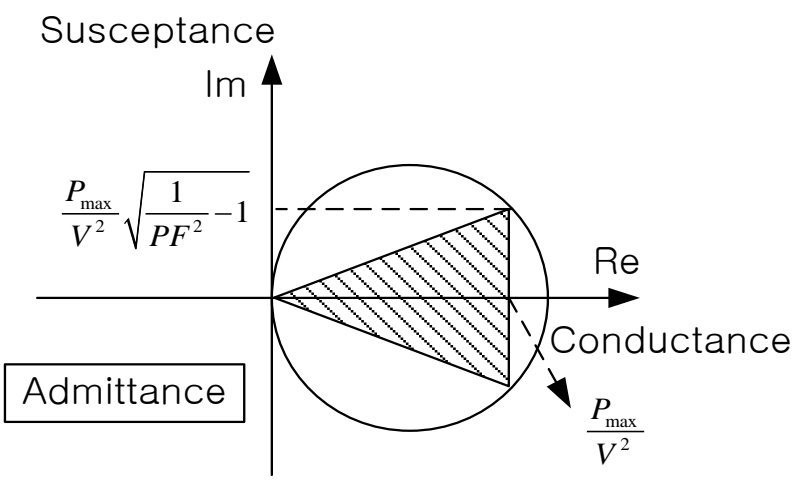

Fig. 6. Permissible range of load admittance and uncertainty.

$$
\frac{1}{\mathrm{Z}}=\mathrm{Y}=\mathrm{G}+\mathrm{jB}
$$

Through equations (3), (4) and (5), the conductance G and susceptance B may be calculated as follows:

$$
\begin{aligned}
& \mathrm{G}=\frac{\mathrm{P}}{\mathrm{V}_{\mathrm{O}}^{2}} \\
& \mathrm{~B}=\frac{\mathrm{Q}}{\mathrm{V}_{\mathrm{O}}^{2}}=\frac{\mathrm{P}}{\mathrm{V}_{\mathrm{O}}^{2}} \sqrt{\frac{1}{\mathrm{PF}^{2}}-1}
\end{aligned}
$$

In addition, when the maximum effective power is $\mathrm{P}_{\max }$, the above equations (5), (6) and (7) show that a range of the admittance of the load is same as the hatched region in Fig. 6 by the fact that $\mathrm{P} \leq \mathrm{P}_{\max }$.

In order to achieve robust performance in the presence of load fluctuations, the uncertainty region of the load admittance is set using a power factor and rating power, as shown in Fig. 6. This will increase the robustness of the system as a very conservative uncertainty representation. Because the uncertainty can be defined by the center and the radius of the complex by using the Robust Control Toolbox in MATLAB, it is defined by a circle on the complex plane through simple algebraic calculations.

When the system model and load model uncertainty are given, a robust voltage controller is designed using $\mu$ -synthesis from the Robust Control Toolbox in MATLAB. Since the order of the designed controller is high, a reduced order Hankel techniques is used to obtain a controller in the fourth order. The transfer function of the designed voltage controller is same as formula (8) [24]. 


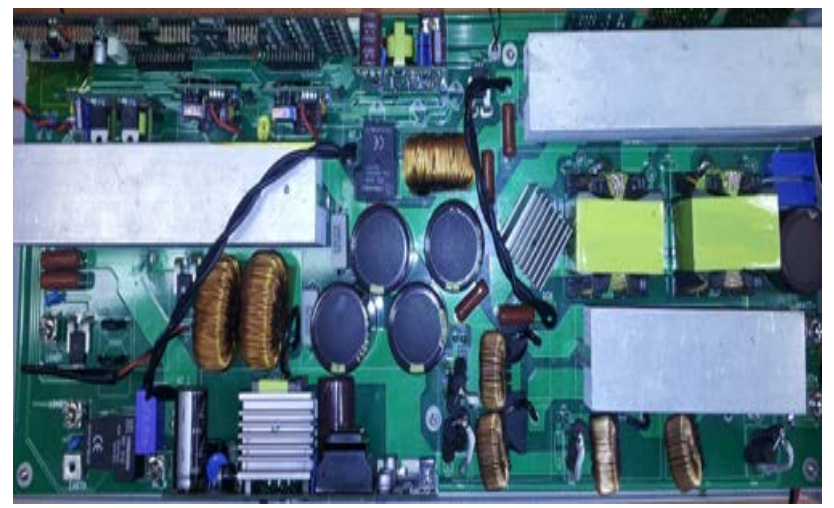

Fig. 7. Experimental equipment of real single-phase UPS.

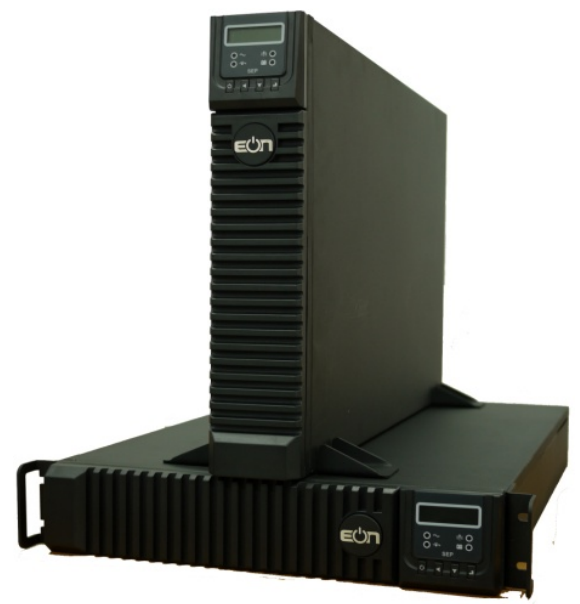

Fig. 8. Product photos of the 3kVA UPS.

$\frac{v_{\mathrm{o}}}{v_{0}^{*}}=\frac{2.57 \times 10^{7} s^{3}-1.016 \times 10^{9} s^{2}+1.649 \times 10^{14} s+3.142 \times 10^{14}}{s^{4}+3.95 \times 10^{5} s^{3}+7.771 \times 10^{10} s^{2}+6.432 \times 10^{11} s+1.104 \times 10^{16}}(8)$

Since the control system of the single-phase UPS inverter is a discrete control system, the transfer function of equation (8) is converted and used as a discrete transfer function through Tustin's bilinear transformation method.

\section{EXPERIMENTAL RESUlts}

Various experiments with a programmable AC and DC power source CSW11100 were carried out to verify the usefulness of the proposed UPS. Fig. 7 shows the experimental equipment made with a real single-phase UPS. Fig. 8 shows a photograph of the developed UPS product which has the width of a 19-inch rack/tower type and a height of $2 \mathrm{U}$.

The rating of the proposed UPS is designed for 3kVA with $60 \mathrm{~Hz}, 220 \mathrm{~V}$ nominal input/output voltages. To handle this power rating, 50A/600V insulated-gate bipolar transistors are selected as power semiconductor switches. These power semiconductor switches are operated with a carrier frequency of $40 \mathrm{kHz} / 19.2 \mathrm{kHz}$ in the PFC/inverter. The system parameters of the fabricated prototype UPS are given in Table I.
TABLE I

SYSTEM PARAMETERS

\begin{tabular}{|l|c|}
\hline Rated output power & $3 \mathrm{kVA}$ \\
\hline Output frequency & $60 \mathrm{~Hz}$ \\
\hline Output voltage & $220 \mathrm{Vrms}$ \\
\hline DC link voltage & $760 \mathrm{~V}$ \\
\hline Switching device, frequency & $\begin{array}{l}\text { PFC : IGBT, } 40 \mathrm{kHz} \\
\text { Inverter : IGBT, } 19.2 \mathrm{kHz}\end{array}$ \\
\hline Inverter output LC filter & $1.5 \mathrm{mH}, 10 \mathrm{uF}$ \\
\hline Boost Inductor & $430 \mathrm{uH}$ \\
\hline DC-Link Capacitor & $680 \mathrm{uF}$ \\
\hline
\end{tabular}

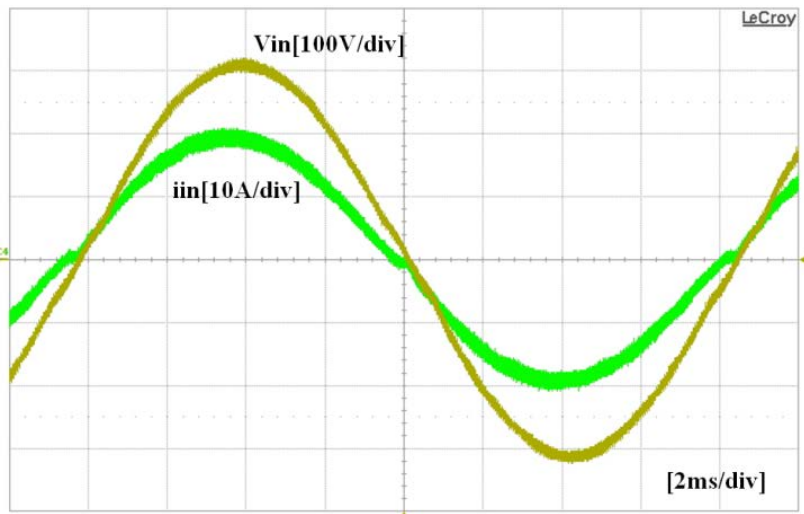

(a)

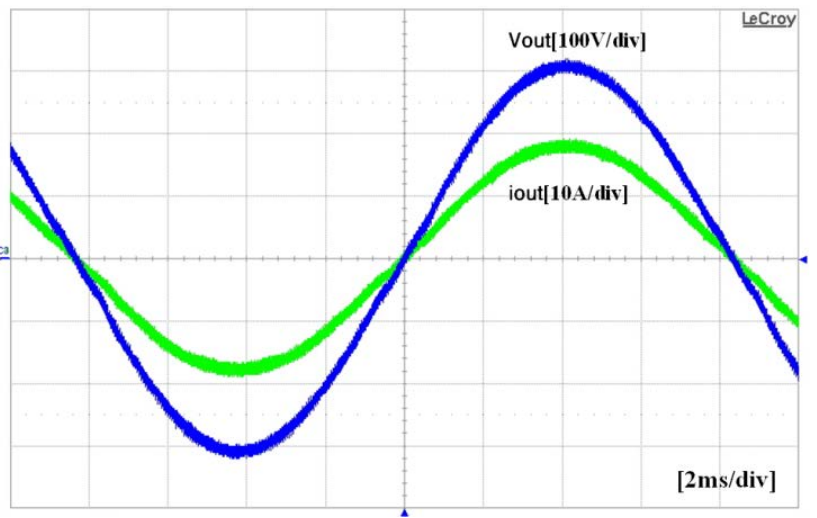

(b)

Fig. 9 Experimental results of normal mode (at 100\% R load). (a) Input voltage and current waveforms of PFC converter $(\mathrm{PF}=0.98$, THDi=2.8\%). (b) Output voltage and current waveforms of inverter $(\mathrm{THDv}=1.8 \%)$.

Figs. 9-12 show various experimental waveforms: input voltage waveform (Vin), input current waveform (iin), DC link voltage waveform (Vdc), output voltage waveform (Vout), and output current waveform (iout) .

Fig. 9 shows the experimental results of the normal mode. Fig. 9(a) shows the input voltage and input current of the UPS under a $100 \% \mathrm{R}$ load. The input current is exactly in phase with the input voltage and nearly sinusoidal. Then the DC bus voltage is controlled to be a constant $760 \mathrm{Vdc}$ by the PFC converter. As a result, the input power factor approaches 


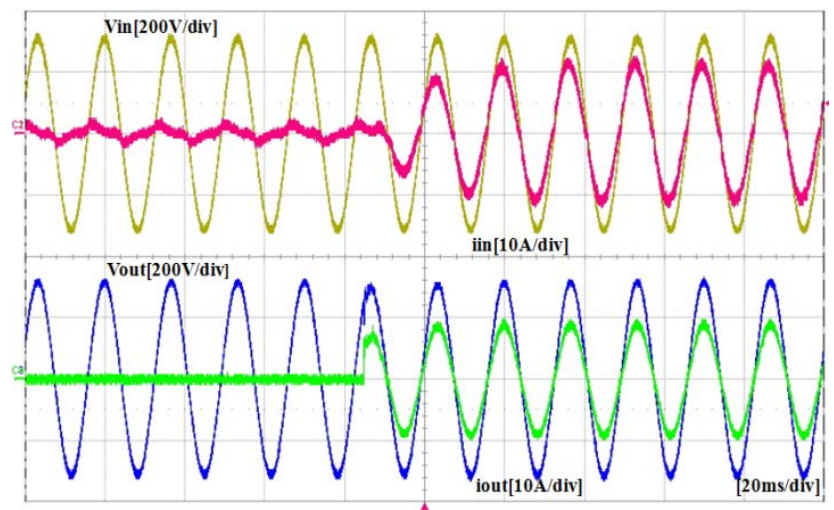

Fig. 10. Experimental results of normal mode at step load ( $0 \%$ load to $60 \%$ load).

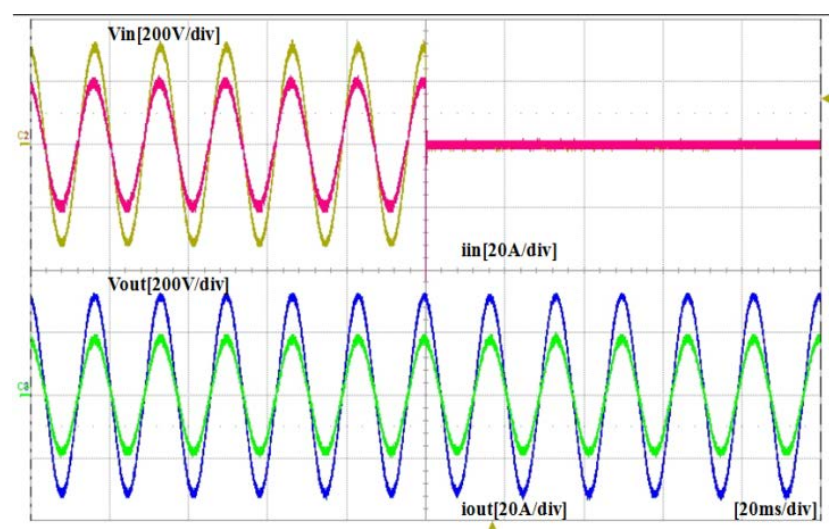

Fig. 11. Experimental results of black-out test (at 100\% R load).

unity. The results, measured by the power meter, show that the total efficiency of the UPS is $95.5 \%$, that the PF is 0.98 , and that the THDi is $2.8 \%$. Fig. 9(b) shows the output voltage and output current under a $100 \% \mathrm{R}$ load and that the THDv of the output voltage is $1.8 \%$.

Fig. 10 shows the experimental results of the normal mode at step load changes from $0 \%$ load to $60 \%$ load. The DC-link voltage is instantaneously decreased. However, it is immediately compensated by the PI voltage controller. The transient effect of the output voltage is negligible and the UPS transfers power to the load. It is shown that both the voltage control and the current control in the PFC converter and inverter are operated well.

Fig. 11 shows the experimental results of the black-out test at a $100 \% \mathrm{R}$ load. It also shows the voltage and current waveforms at the loss of input power. The waveform of the output voltage is normally same as the output in the battery mode even when the input voltage is interrupted by a power failure. The battery discharger operates as a boost converter while changing the operation mode of the UPS from the normal mode to the battery mode.

Fig. 12 shows the experimental results of the restoration test at a $100 \% \mathrm{R}$ load. The phase of output voltage is synchronized with the phase of the input voltage by the PLL, and the UPS returns to the normal mode when the input

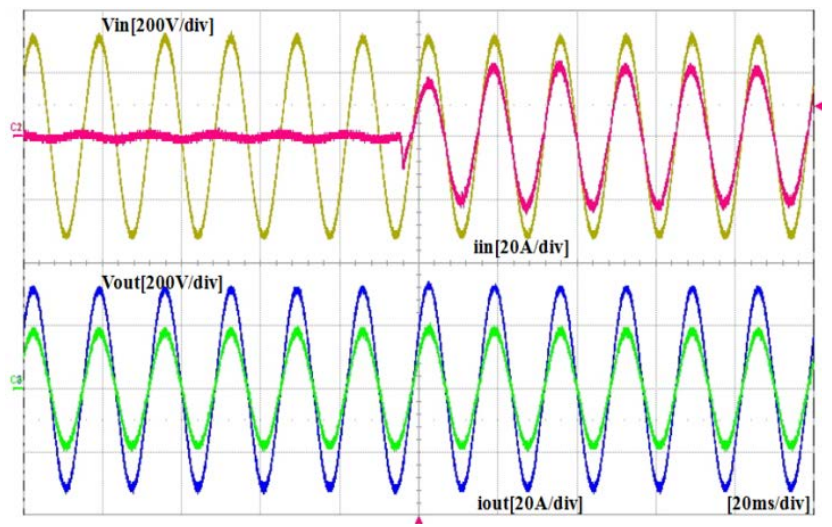

Fig. 12. Experimental results of restoration test (at 100\% R load).

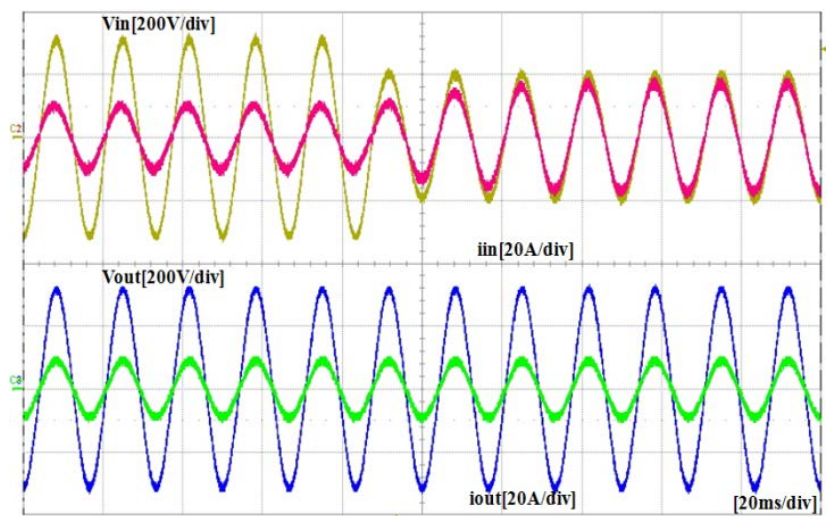

Fig. 13. Experimental results of under voltage (at $60 \% \mathrm{R}$ load).

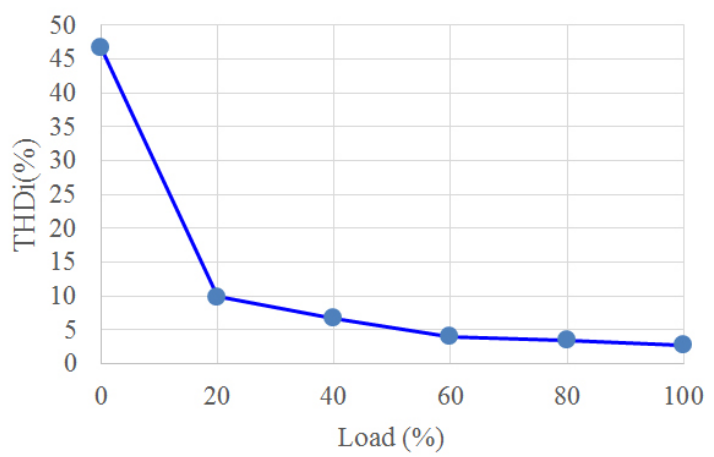

(a)

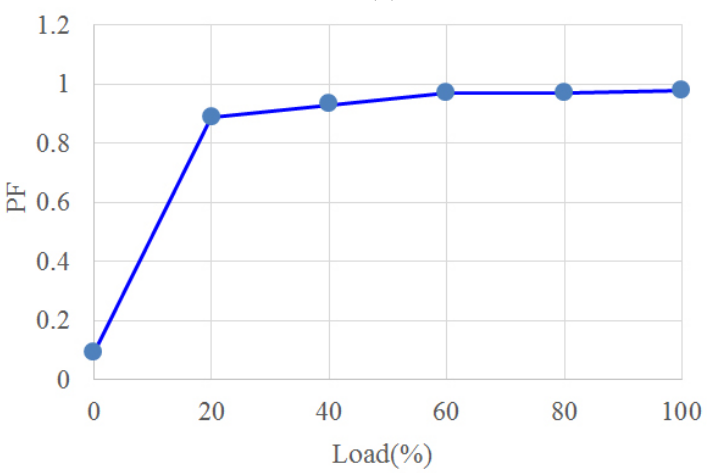

(b)

Fig. 14. THDi of input currrent and input power factor (a) THDi of input current. (b) Input power factor. 


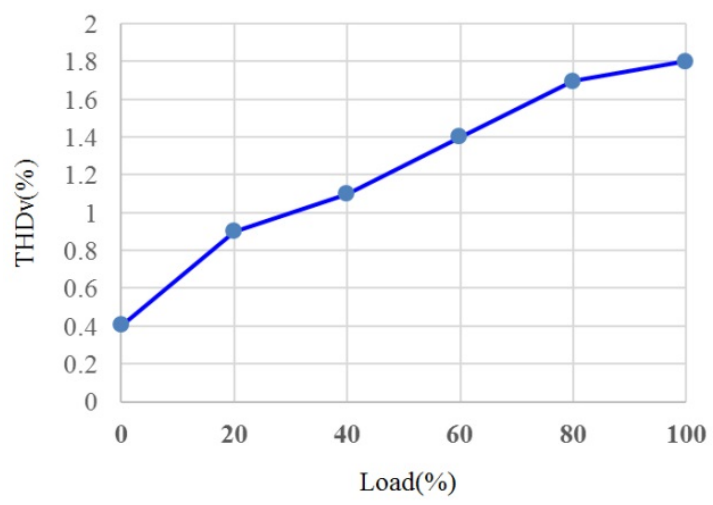

Fig. 15. THDv of inverter output voltage at R load.

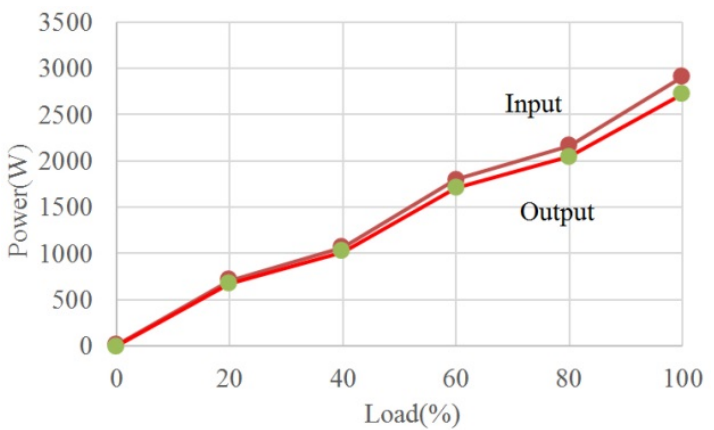

(a)

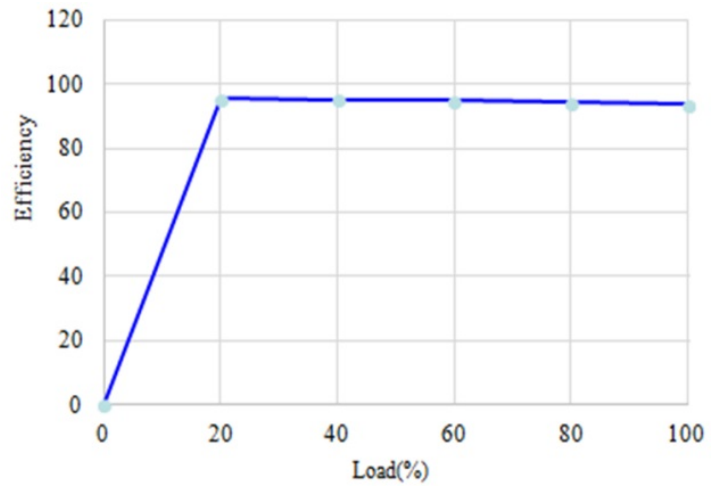

(b)

Fig. 16. Power and efficiency of proposed 3kVA UPS. (a) Input and output power. (b) Efficiency.

voltage is back to normal. Figs. 11 and 12 show that proposed UPS transfers power seamlessly to the load.

Fig. 13 shows the experimental results of the under voltage condition at a $60 \% \mathrm{R}$ load. Although the input voltage is suddenly changed from $220 \mathrm{~V}$ to $140 \mathrm{~V}$, inverter output voltage is unchanged.

Fig. 14 shows the THDi of the input currrent and input power factor at the R load test. As shown in Fig. 14(b), the power factor of proposed 3kVA UPS is nearly 0.98 in a load condition greater than a $60 \%$ load.

Fig. 15 shows the THDv of the inverter output voltage at the $\mathrm{R}$ load test. As shown in Fig. 15, the THDv of the output voltage in the proposed $3 \mathrm{kVA}$ UPS is always lower than $2 \%$.

Fig. 16 shows the input power, output power and efficiency of the proposed 3kVA UPS at the R load test. As shown in Fig. 16(b), the efficiency of the proposed 3kVA UPS is nearly 95\% in a load condition greater than $20 \%$. It can be seen that the validity of the proposed single phase double-conversion UPS with a low cost and high performance using a single-loop robust voltage controller and a 1-switch voltage doubler strategy PFC has been verified by various experimental tests.

\section{CONCLUSION}

In this paper, a low cost, high-performance double-conversion UPS using a single-loop robust voltage controller and a 1-switch voltage doubler strategy PFC converter has been proposed. The proposed UPS was developed with the width of a 19-inch rack/tower type and a height of 2U. The PFC converter and inverter supply energy to the load in the normal mode. The inverter also operates in the power failure mode and supplies energy to the load with a push-pull converter and a battery. Through the normal mode operation, power black-out and power recovery tests, the usefulness of the proposed UPS was verified. The experimental results also show that the proposed UPS has good dynamic and steady-state performance.

\section{ACKNOWLEDGMENT}

This work was supported by the Soonchunhyang University Research Fund (Project No. : 20110692)

\section{REFERENCES}

[1] S. Karve, "Three of a kind UPS topologies, IEC standard,” IEE Review, Vol. 46, No. 2, pp. 27-31, Mar. 2000.

[2] W. Solter, "A new international UPS classification by IEC 62040-3," in Proc. International Telecommunications Energy Conf., pp. 541-545, 2002.

[3] S. B. Bekiarov and A. Emadi, "Uninterruptible power supplies: classification, operation, dynamics, and control," APEC 2002, Vol. 1, pp. 597-604, 2002.

[4] Limits for Harmonic Current Emissions (Equipment Input Current up to and Including 16A Per Phase), IEC Std. 61000-3-2, 2009.

[5] IEEE Recommended Practices and Requirements for Harmonic Control in Electrical Power Systems, IEEE Std. 519-1992, 1992.

[6] J. C. Salmon, "Circuit topologies for single-phase voltage-doubler boost rectifiers", IEEE Trans. Power Electron., Vol. 8, No. 4, pp 521-529, Oct. 2004.

[7] W.-J. Ho, M.-S. Lin, and W.-S. Feng, "Common-neutral-type AC/DC/AC topologies with PFC pre-regulator,” PEDS 1997, Vol. 1, pp. 53-58, 1997.

[8] W. Zhang, G. Feng, Y.-F. Liu, and B. Wu, "A digital power factor correction (PFC) control strategy optimized for DSP,” IEEE Trans. Power Electron., Vol. 6, No. 6, pp. 1474-1485, Nov. 2004.

[9] G.-J. Su, D. J. Adams, and L. M. Tolbert, "Comparative study of power factor correction converters for single 
phase half-bridge inverters,” PESC 2001, Vol. 2, pp 995-1000, 2001.

[10] D. M. Van de Sype, K. De Gusseme, A. P. M. Van den Bossche, and J. A. Melkebeek, "Duty-ratio feedforward for digitally controlled boost PFC converters", IEEE Trans. Ind. Electron., Vol. 52, No. 1, pp 108-115, Feb. 2005.

[11] S. Wall and R. Jackson, "Fast controller design for single-phase power-factor correction systems," IEEE Trans. Ind. Electron., Vol. 44, No. 5, pp 654-660, Oct. 1997.

[12] Y.-K. Lo, T.-H. Song, and H.-J. Chiu, “Analysis and elimination of voltage imbalance between the split capacitors in half-bridge boost rectifiers," IEEE Trans. Ind. Electron., Vol. 5, No. 5, pp 1175-1177, Oct. 2002.

[13] D.-Y. Koo, D.-W. Kim, S.-B. Lim, and S.-C. Hong, “A study on the power factor improvement of single-phase bridgeless voltage doubler converter," in Proc. 2011 Power Electronics Autumn Conference, pp. 169-170, Nov. 2011.

[14] P. C. Loh, M. J. Newman, D. N. Zmood, and D. G. Holmes, "A comparative analysis of multi-loop voltage regulation strategies for single and three-phase UPS systems,” IEEE Trans. Power Electron., Vol. 18, No. 5, pp. 1176-1185, Sep. 2003.

[15] M. J. Ryan and R. D. Lorenz, “A high-performance sine wave inverter controller with capacitor current feedback and "Back-EMF" decoupling," Conf. Rec. IEEE-PESC, pp. 507-513, 1995.

[16] P. C. Loh and D. G. Holmes, “Analysis of multiloop control strategies for LC/CL/LCL-filtered voltage-source and current-source inverters,” IEEE Trans. Ind. Appl., Vol. 41, No. 2, pp. 644-654, Feb. 2005.

[17] M. J. Ryan, W. E. Brumsickle, and R. D. Lorenz, "Control topology options for single-phase UPS inverters”, IEEE Trans. Ind. Appl., Vol. 33, No. 2, pp. 493-501, Feb. 1997.

[18] T. S. Lee, S. J. Chiang, and J. M. Chang, "Hळ loop-shaping controller designs for the single-phase UPS inverters," IEEE Trans. Power Electron., Vol. 14, No. 4, pp. 473-481, Jul. 2001.

[19] L. Giuntini, "Harmonics reduction in high-efficiency operation of double-conversion UPS," in Proc. European Conference on Power Electronics and Applications, pp. 1-10, 2011.

[20] F. Cammarota, and S. Sinigallia, "High-efficiency on-line double-conversion UPS,” Proc. International Telecommunications Energy Conf., pp. 657-662, 2007.

[21] S.-B. Lim, Y.-H. Lee, J.-K. Ji, and S.-C. Hong, "Development of single phase UPS for low cost and high performance," Proc. 2011 Power Electronics Autumn Conference, pp. 199-200, 2011.

[22] D.-K. Ku, J.-K. Ji, G. Cha, S.-B. Lim, and S.-C. Hong, "Operation characteristic of single-phase PFC converter with 1-switch voltage doubler strategy," Transactions of Korean Institute of Power Electronics(KIPE), Vol. 16, No. 6, pp. 561-568, Dec. 2011.
[23] D.-K. Ku, J.-K. Ji, G. Cha, S.-B. Lim, and S.-C. Hong, "Comparison of current control method for single-phase PFC converter with 1-switch voltage doubler strategy," Transactions of Korean Institute of Power Electronics(KIPE), Vol. 17, No. 1, pp. 1-7, Feb. 2012.

[24] D.-K. Ku, J.-K. Ji, G.-S. Cha, and J.-H. Moon, "Design of robust voltage controller for single-phase UPS inverter," Transactions of Korean Institute of Power Electronics(KIPE), Vol. 16, No. 4, pp. 317-325, Aug. 2011.

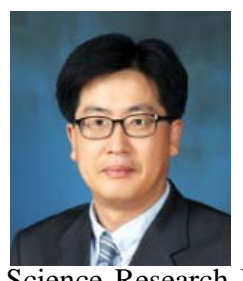

Jun-Keun Ji was born in Seoul, Korea, in 1964. He received his B.S., M.S., and Ph.D. degrees in Electrical Engineering from Seoul National University, Seoul, Korea, in 1986, 1988, and 1994, respectively. From 1991 to 1994 , he was a Research Engineer with the Korea Electrical Engineering and Science Research Institute (KESRI), Korea. Since 1994, he has been a Faculty Member in the Department of Electrical Engineering, Soonchunhyang University, Choongnam, Korea. He is presently a Publication Editor of the Journal of Power Electronics, Seoul, Korea. His current research interests include electric machine drives, power converter control techniques, power quality issues, and motion control applications.

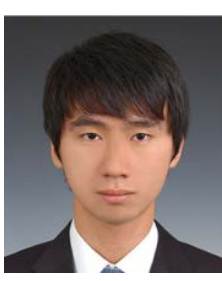

Dae-Kwan Ku was born in Korea, in 1986. He received his B.S. and M.S. degrees in Electrical Engineering from Soonchunhyang University, Choongnam, Korea, in 2010 and 2012, respectively. Since 2012, he has been a Research Engineer with VCTech Co., Ltd., Gunpo, Korea. His current research interests include induction motor drive systems for neighborhood electric vehicles and ac-motor sensorless drives.

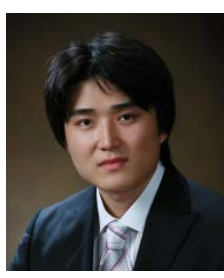

Seung-Beom Lim was born in Korea, in 1979. He received his B.S., M.S., and Ph.D. degrees in Electrical Engineering from Dankook University, Yongin, Korea, in 2004, 2006, and 2014, respectively. Since 2007, he has been a Senior Research Engineer with EON Co., Ltd., Anyang, Korea. His current research interests include multi-level converters/inverters, high-power density converter/inverter design, and modular UPSs (Uninterruptible Power Supplies). 